\title{
Exercícios de coralidade A APCT em Guimarães
}

\section{Rui Pina Coelho e Rita Martins}

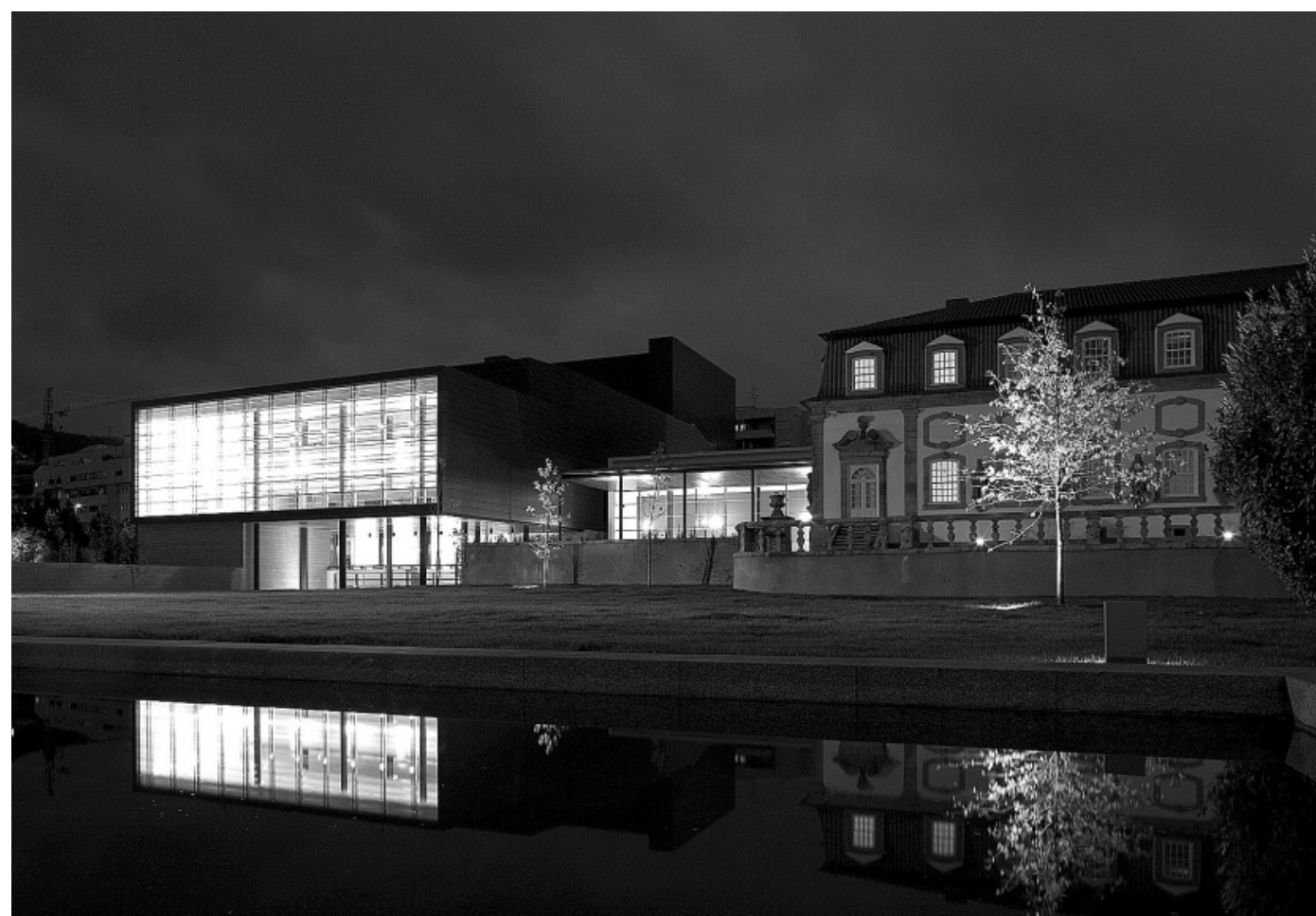

Visando contrariar o progressivo - e visivel desaparecimento da crítica de teatro nos órgãos de comunicação generalistas e estimular a criação de pólos regionais de críticos atentos à actividade teatral de todo o país, a Associação Portuguesa de Críticos de Teatro implementou, em 2010, a realização de Seminários para Novos Críticos. A primeira edição decorreu no âmbito dos Festivais Gil Vicente, em Guimarães, sob orientação de Rita Martins e Rui Pina Coelho, de 10 a 13 de Junho de 2010, tirando partido da diversidade e da qualidade geral da programação.

0 modelo, inspirado nos Seminários Internacionais para Novos Críticos promovidos pela Associação Internacional de Críticos de Teatro (AICT), baseia-se essencialmente no visionamento e na análise de espectáculos. A discussão sobre cada um dos espectáculos serve para exercitar os instrumentos específicos de análise dos diferentes componentes da cena, visando uma justa adequação aos espectáculos em questão. Estes Seminários são também um lugar para discutir o papel da crítica e as suas razões históricas, bem como para experimentar a escrita de textos críticos com vista à sua publicação.

Os participantes, jovens criticos, jornalistas, estudantes de teatro e de artes performativas - oriundos de Lisboa, Guimarães e Coimbra -, assistiram aos espectáculos Uma familia portuguesa, enc. Cristina Carvalhal (Teatro Aberto/SPA), Ivanov, enc. Tónan Quito (Truta), Han Shot First, de Diogo Bento e Inês Vaz, e Hedda Gabler, enc. Bruno Bravo (Primeiros Sintomas), tendo tido oportunidade de interpelar criadores e programadores, tais como Cristina Carvalhal, Teresa Faria, João Pedro Vaz, Marcos Barbosa (Teatro Oficina) e José Bastos (Centro Cultural Vila Flor). Aqui publicamos alguns dos textos resultantes deste Seminário.
Rita Martins

é critica de teatro e investigadora do Centro de Estudos de Teatro da Universidade de Lisboa. Publicou em 2007 um estudo sobre Raul Brandão: Do texto à cena e, em 2006, uma Introdução e Notas ao Teatro completo de D. João da Câmara na Imprensa Nacional - Casa da Moeda. 

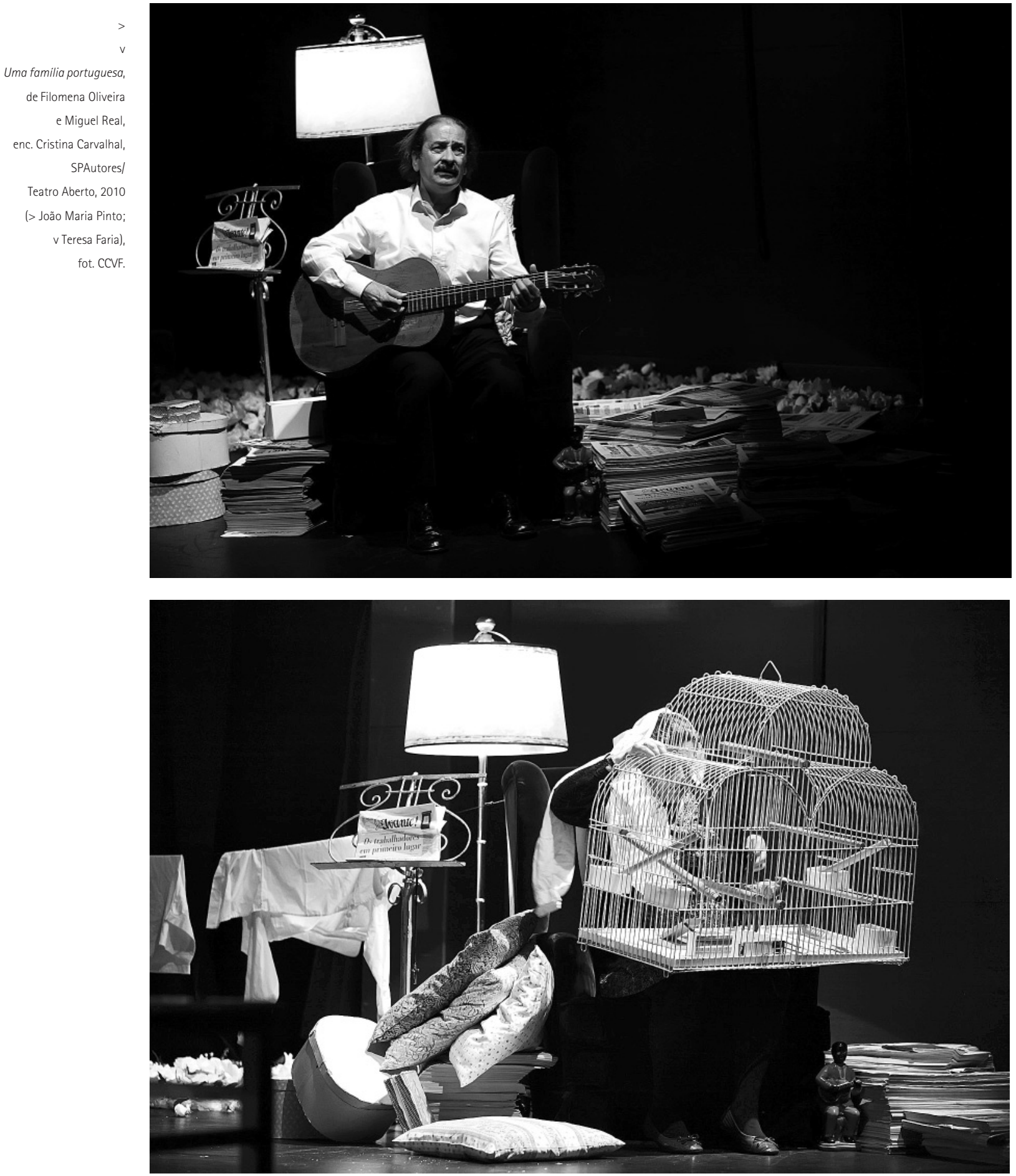

Titulo: Uma família portuguesa. Texto: Filomena Oliveira e Miguel Real. Dramaturgia e encenação: Cristina Carvalhal. Música: João Gil. Cenário: Ana Vaz. Figurinos: Ana Vaz e Maria Gonzaga. Luz: Melim Teixeira. Apoio ao movimento: Margarida Gonçalves. Interpretação: Bruno Simões, Carlos Malvarez, João Maria Pinto, Luisa Salgueiro, Teresa Faria. Produção: SPAutores/ Teatro Aberto. Local e data de apresentação nos Festivais Gil Vicente: Pequeno Auditório, Centro Cultural Vila Flor, 10 de Junho 2010

Teatro de reconhecimento

Susana Chicó

Susana Chicó frequenta o Mestrado em Estudos de Teatro na FLUL e trabalha em

investigação no

Chapitô.
No convencionado Dia de Portugal, os Festivais Gil Vicente em Guimarães, apresentaram um espectáculo castiço. Uma familia portuguesa, de Filomena Oliveira e Miguel Real, encenado por Cristina Carvalhal, é um retrato frenético, carinhoso e parodicamente "coitadista" das famílias nacionais.
O cenário caótico de Ana Vaz suga imediatamente o espectador para a casa da viúva portuguesa. Há centenas de objectos a atafulhar o palco: um altar a Fátima, incontáveis bibelôs de loiça, penicos, gaiolas, estendal, lençóis, televisões estragadas, poltronas velhas e dezenas de jornais empilhados. Encurralada neste ambiente bafiento, vive uma alvoroçada família afectivamente centrada numa avó esclerosada. As personagens são esmagadas por 
rançosas memórias familiares e fantasmas nacionais: um avô falecido tem ainda lugar à mesa, o saudosismo fascista afirma-se na senilidade da avó, o pai revive os traumas da guerra colonial e as desilusões políticas do 25 de Abril, e é ainda marcado o escapismo gastronómico nas ansiadas patuscadas com camarão-miúdo.

0 notável elenco (José Maria Pinto, Luisa Salgueiro, Bruno Simões, Carlos Malvarez e Teresa Faria) cumpre as tarefas quotidianas a uma velocidade alucinante ao ritmo físico do slapstick, concedendo ao espectáculo uma respiração, ou antes, uma hiperventilação ansiosa que grita uma cultura do desenrascanço. A musicar esta farsa trágica está o incontornável fado e o clássico $E$ depois do adeus de Paulo de Carvalho, que fecha este espectáculo com uma nota tragicómica.

Satiriza-se aqui a lamúria portuguesa, mas reivindicase a identificação e a compreensão no frenesim afectivo que é sempre bem-intencionado embora provisório e incompetente, um penso rápido para problemas de acumulação geracional. Já diziam os romanos que aqui vive um povo que não se governa nem se deixa governar. A encenação de Cristina Carvalhal destila precisamente este espirito nacional que vive da solução de última hora, da espiritualidade vã, da desresponsabilização e do queixume, registando-se na cómica aceleração interpretativa e na claustrofobia cénica uma observação desesperante: a constante desorganização nacional.

Uma familia portuguesa é teatro pavloviano, é um excelente teatro de reconhecimento, repleto de lugares comuns, que identificam a nossa nação. Só falta mesmo o cheiro a mofo e a naftalina para activarmos a saudade e a ilusão de um futuro melhor.

\section{Uma família bem portuguesa}

José Alves de Carvalho ${ }^{2}$

0 espectáculo apresenta-nos uma familia onde três gerações coabitam na casa que receberam do patriarca. A velha Isaura (Teresa Faria), que julga o marido ainda vivo; "janta" e "dorme" com ele para desespero da nora (Luisa Salgueiro), que não se consegue afirmar perante aquele fantasma. José (João Maria Pinto), o marido reformado, é um antigo combatente em África e, acima de tudo, um homem derrotado. Foi defender a pátria e acabou por perder os seus ideais. E os filhos, que não têm vida própria, ameaçam sair de casa, mas nunca o fazem. A excepção chama-se Joana, a filha ausente que, para sua desgraça, rompe com a barreira do espaço familiar, mas acaba por morrer na sequência de um aborto.

São várias as histórias possiveis, mas nenhuma delas nos é contada em particular. São antes maneiras de convocar temas como a guerra colonial, o "chicoespertismo" ou a devoção a Nossa Senhora de Fátima. No cenário de Ana Vaz encontramos um sem número de objectos reconhecíveis (porque comuns a tantas casas portuguesas). Excessivo, o espaço cénico não é mais do que uma imensa barreira que aquela família não é capaz ou não quer transpor. Sendo exíguo e labirintico este espaço, não impede que as personagens se movimentem com destreza e à vontade naquele que pode ser considerado o habitat natural de muitas famílias portuguesas.

Assim, as sequelas da guerra colonial ou a falta de dinheiro, afinal de contas, mais não são do que a desgraça daquela família que, ainda assim, nos é apresentada em tom de comédia. No fim, ainda que pelo pior dos motivos (a morte de um filho), aquela familia parece libertar-se de todos os fantasmas. Mas a sensação que fica é de que raramente consegue ir para onde quer que seja. Em Uma familia portuguesa parece que, por muitos obstáculos que se tirem do caminho, nunca se consegue sair do mesmo sítio.

\section{Uma família portuguesa, com certeza} Stat Miller ${ }^{3}$

No dia da comemoração da Nação assistimos à última criação artística de Cristina Carvalhal: Uma familia portuguesa. A narrativa, as personagens e o cenário em que estas se movimentam são reconhecidamente nacionais. As referências musicais, plásticas e temáticas da segunda metade do século XX convocam um imaginário com o qual (quase) todos os portugueses se identificam. Num ambiente doméstico atafulhado de bibelôs, o espectáculo abarca as permanentes discussões desta familia constituída por três gerações: os problemas do cancro, a fervorosa crença religiosa, as discussões entre nora e sogra, os filhos que tardam em sair de casa depois de já adultos, o aborto, os traumas advindos das guerras coloniais e o fantasma do fascismo.

0 que surge em cena é o contexto luso em tom cómico ritmado e extremamente coreografado, envolvendo os actores que habitam esse espaço de memória e contemporaneidade. A empatia que estabelecemos com o espectáculo resulta da moldura estética made in Portugal, que investe num trabalho aprofundado de reflexão e exposição particularizada em múltiplos elementos cénicos. Estes correriam o risco de serem apenas um cliché ou uma imagem superficial de uma família portuguesa, mas a inteligência do espectáculo encontra-se precisamente nesse limbo entre o reconhecivel e caricatural e o mais particularizado e profundo.

Com um trabalho artístico de uma beleza metafórica e poética, Cristina Carvalhal evoca em palco o Portugal de hoje e entramos todos juntos em cena com esta familia portuguesa, que tem, com certeza, um pouco de todos nós.

\section{Uma sucessão de espectros}

Samuel Silva ${ }^{4}$

Começa com uma luz ténue. A história desta familia portuguesa - que podia ser a nossa - é uma sucessão de espectros: a guerra colonial e Fátima; a política e o dinheiro; o aborto e a doença. E é uma narrativa desconfortavelmente familiar. Somos convidados a entrar numa casa cheia de tralha. É este o cenário: uma espécie de campo arqueológico
${ }^{2}$ José Alves de Carvalho, licenciado em Comunicação Social pela Escola Superior de Jornalismo do Porto, é jornalista e editor do jornal Entre Margens ex-director de Informação na Rádio Universitária do Minho.

${ }^{3}$ Stat Miller frequenta o Mestrado de Teatro, especialização em Encenação, na ESTC.

\footnotetext{
${ }^{4}$ Samuel Silva

é jornalista,

colaborando com

regularidade no jornal Público e no semanário O Povo de Guimarães, onde se tem dedicado sobretudo à cultura.
} 
das memórias desta familia. E sentimo-nos tão aconchegados na proximidade dos referentes culturais que o cenário e os figurinos convocam, como desconcertados por nos revermos naquele sofrimento.

0 espectáculo encenado por Cristina Carvalhal estica a corda até quase a fazer partir. Porque tememos que o tom cómico adoptado termine num humor revisteiro, ou que as personagens deixem resvalar a sua tipificação numa caricatura descarnada. Mas esse limite nunca é ultrapassado. 0 melhor exemplo é a sobriedade com que esta tragédia familiar é resolvida, sem cair em excesso melodramático: um quase-bailado que fecha o espectáculo pinta de vermelho aquele mundo de sombras.

Este é, por isso, um produto de um certo momento português em que reviver o passado é uma urgência. Mas não é já dolorosa, como para aquelas personagens, mas catártica, como se precisássemos de viver o sofrimento deles para os podermos esquecer. 0 mérito da equipa de Cristina Carvalhal está em ter sido capaz de o fazer de forma elegante.
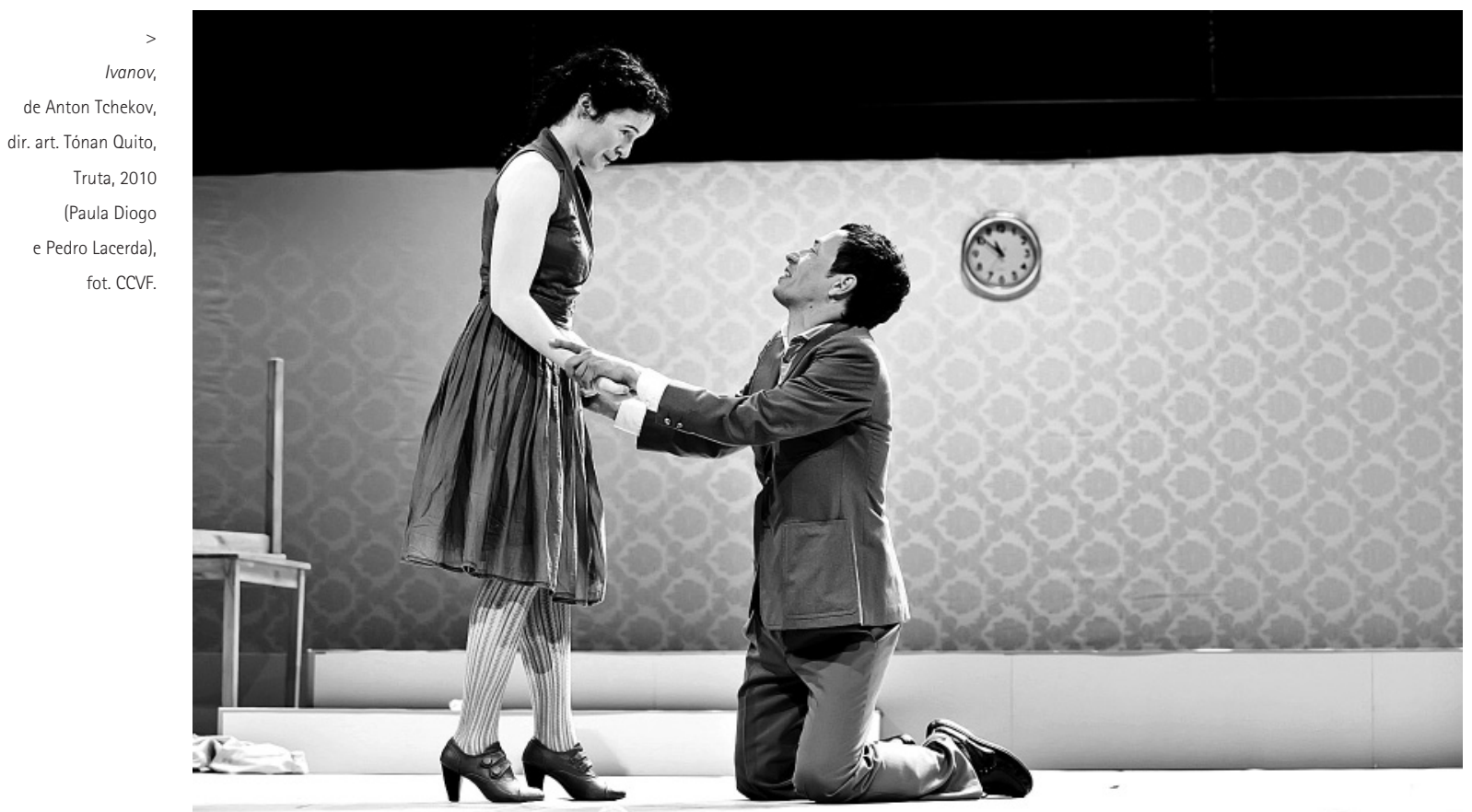

Título: Ivanov. Texto: Anton Tchekov. Tradução: José Sinde Filipe (revista por Luis Lima Barreto). Direcção artística: Tónan Quito. Direcção musical: Melech Mechaya. Cenografia: F. Ribeiro. Figurinos: Ana Limpinho. Desenho de luz: Daniel Worm d'Assumpção. Interpretação: António Fonseca, Carla Galvão, Carla Maciel, João Pedro Vaz, Joaquim Horta, Paula Diogo, Pedro Lacerda, Raul Oliveira, Rita Durão, Silvia Filipe e Tónan Quito. Músicos: Francisco Caiado, João Graça, João Novais, Miguel Verissimo. Produção: Truta, Teatro Maria Matos. Local e data de apresentação nos Festivais Gil Vicente: Grande Auditório, Centro Cultural Vila Flor, 11 de Junho 2010.

Uma súmula de talentos individuais em prol de um espectáculo colectivo Jorge Geraldo ${ }^{5}$

0 mais recente trabalho do colectivo Truta, Ivanov, de Anton Tchékov, surge numa lógica de validação artística e num recuperar de um texto clássico bastante pertinente.

5 Jorge Geraldo, licenciado em Estudos

Artísticos pela

Faculdade de Letras da

Universidade de

Coimbra, está terminar a sua tese de Mestrado na mesma
0 espectáculo anda em torno de Nicolai Ivanov, um homem desprovido de esperança e ambição, um espectro errante amarrado a um casamento que o entedia, mesmo que este seja limitado por um claro prazo de validade, já que à sua esposa tuberculosa não resta muito tempo de vida. 0 tédio em que Ivanov se vê mergulhado é uma constante, algo transversal a todos os personagens, que procuram vários subterfúgios para a fuga ao real. Todos eles procuram o que não podem ter, seja uma vida facilitada pelo dinheiro por negociatas, um amor impossivel, um casamento por conveniência ou a simples coragem para se libertarem do que os oprime.

Há contudo, um constante sentimento festivo, bem transmitido pela presença dos músicos em palco, a banda Melech Mechaya: um violino, uma guitarra, um contrabaixo, um clarinete e percussão. A pândega é selvática, é uma falsa alegria que mascara o real com o propósito de fugir à melancolia dominante. Aponta-se para uma realidade onde aos vinte anos se é herói, e aos trinta não se é nada, encarando-se o insucesso como a perdição de uma existência vazia. 0 que domina é o sentimento de recusa constante da felicidade - onde o amor é válido - parecendo, 


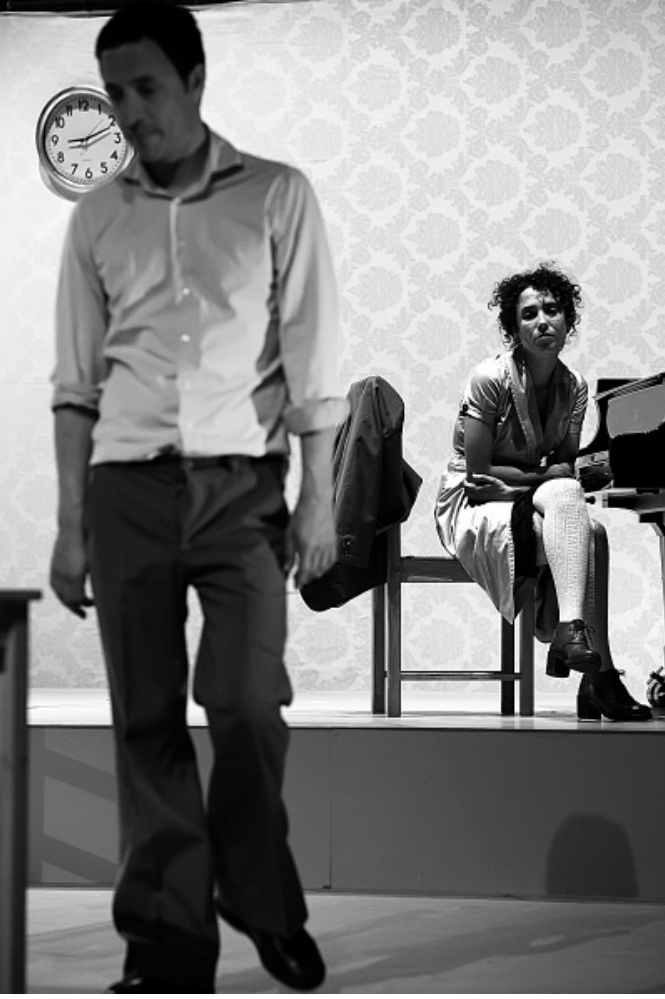

antes, que o mais importante é a festa, e onde tudo parece precipitar a queda, o infortúnio e o desencanto.

0 espectáculo assenta essencialmente no seu talentoso elenco, com prestações muito válidas, com pouca repercussão na problemática/enigmática falta de direcção artística, onde o espaço amplo - apenas povoado por mesas, cadeiras, um piano, um relógio e um cão de loiça - acaba por ser meramente acessório, ou poderá ser muito mais. Claramente com uma viagem bem definida, mas um destino ainda algo nublado.

Não posso esquecer a pistola: é com ela que se inicia o espectáculo e é com ela que termina, num fechar de ciclo inevitável, onde o encanto se torna uma realidade, onde os ponteiros do relógio se detêm finalmente. 0 colectivo Truta consegue um bom Ivanov com uma saudável dissonância entre o cómico e o trágico, onde os elementos são marcados por um fatalismo ao qual é impossivel escapar.

\section{Ivanov}

José Alves de Carvalho

Esta é uma segunda incursão da Associação Cultural Truta por um texto clássico. Neste caso, Ivanov, de Anton Tchekov com direcção artística de Tónan Quito, apresentado no âmbito dos Festivais Gil Vicente (Guimarães).

Ivanov, um proprietário rural endividado e - pior do que isso - incapaz de reagir, é aqui materializado por um apático Pedro Lacerda, sem que se consiga perceber se o registo abona mais a favor da personagem ou a desfavor do intérprete. Um anti-herói, como é descrito no programa do espectáculo, a braços com uma esposa, Anna Petrovna (Rita Durão), que já não ama e que, mesmo sabendo que sofre de tuberculose, nada faz para a salvar.Não abdica, ainda assim, de frequentar as festas na casa dos Lebedev, por onde se passeia uma série de personagens, excessivas na forma de estar, mas nem por isso menos desgraçadas e mesquinhas. E depois há o médico de Anna: figura que se passeia pelo centro do palco e que surge aos olhos do público de forma enigmática. Mesmo cheio de princípios e encarnando a verdade, o médico, interpretado por Raul Oliveira, é de um aborrecimento tal que cria mais antipatia no público do que o contrário. Este - o público - quererá estar do lado da farra.

Com uma solução cénica reduzida ao mínimo e eficaz na transição que é feita do espaço de trabalho de Ivanov para o da festa do seu casamento com Sacha, o tom do espectáculo é dado, primeiro, pelo conde e tio de Ivanov (António Fonseca) e depois pelo pai de Sacha (João Pedro Vaz). São eles que nos fazem rir ao longo do espectáculo, convocando-nos para a farra que se instala no palco, ampliada ainda com a entrada em cena de um grupo de músicos.

Escrita em finais de século XIX, este Ivanov, levado à cena pela Truta, surge sem tempo. Mérito, por um lado, do próprio Nicolai Ivanov - personagem intemporal na sua incapacidade de reagir -, e da actualização da linguagem que, no entanto, não encontra paralelo no guarda-roupa datado da maioria das personagens.

Ivanov resulta assim num espectáculo cativante, apesar do desequilibrio do colectivo de actores e do seu - menos feliz - processo de actualização.

\section{Revisitar lvanov}

Hélder Wasterlain ${ }^{6}$

Escrito em 1887, Ivanov foi o primeiro texto dramático do autor russo a ser encenado. Apesar de na altura não ter recebido as melhores críticas, e de o próprio autor ter ficado um pouco desiludido com a forma como os actores o interpretaram, obrigando-o a reescrevê-lo, Ivanové um texto cuja temática ainda hoje merece a nossa reflexão. Nicolai Ivanov (Pedro Lacerda) é um poeta perdido, desorientado e deprimido. Com 35 anos, a sua vida está à beira de um precipício. Entre a incapacidade de agir e a vontade de mudar vai um passo. Um passo que nem Ivanov nem as restantes personagens são capazes de dar, porque a mudança não é exterior, mas interior, e esta exige outras forças, outros homens e mulheres que não estes. No final, só Ivanov muda, mas muda para sempre.

Uma aura de tédio e fracasso transparece deste texto, contaminando inclusivamente as opções cénicas propostas. Um cenário despido e desértico, como se não tivesse havido vontade de fazer mais, povoado por objectos simples: um piano de cauda, marco distintivo de uma certa burguesia; um pano creme, semelhante a papel de parede, como pano de fundo e com um relógio pregado a meio a marcar um tempo muito particular; um inusitado cão de loiça, mais algumas mesas e cadeiras. Ou seja, sóbrio como o deserto.

Sob a direcção artística de Tónan Quito, a adaptação de Ivanov acaba por salientar dois aspectos: coerência e inteligência. Aliando momentos de muita comicidade com momentos de um silêncio inquietante e desconfortável,
Ivanov $_{\text {, }}$

de Anton Tchekov,

dir. art. Tónan Quito,

Truta, 2010

(Pedro Lacerda

e Rita Durão), fot. CCVF.

${ }^{6}$ Hélder Wasterlain frequenta $03^{\circ}$ ano de Teatro, Ramo Dramaturgia na ESTC e é dramaturgo e fundador do grupo ÉSÓFACHADA. 
a falência humana, que está a ser representada, nunca resvala para uma catártica tragédia. Tudo é leve para que o texto assuma o seu peso e inquietação.

Destaque para o elenco: maioritariamente jovem, de grande qualidade, servindo o texto de forma simples e eficaz. Nota-se, no entanto, alguma ausência de direcção de actores, que sem surpresas apenas reafirmam a qualidade demonstrada noutros trabalhos. A individualidade afirmase, mas o sentido de grupo dilui-se.
Fundada em 2003, a Associação Cultural Truta pautase pela vontade de explorar vários discursos e linguagens artísticas. A escolha de autores incontornáveis para a história do teatro poderá ser um caminho para este grupo e sobretudo para uma nova geração de espectadores que espera sempre a marca da contemporaneidade nestas revisitações.

\section{de Diogo Bento e Inês Vaz, 2010 (Inês Vaz e Diogo Bento), fot. CCVF.}

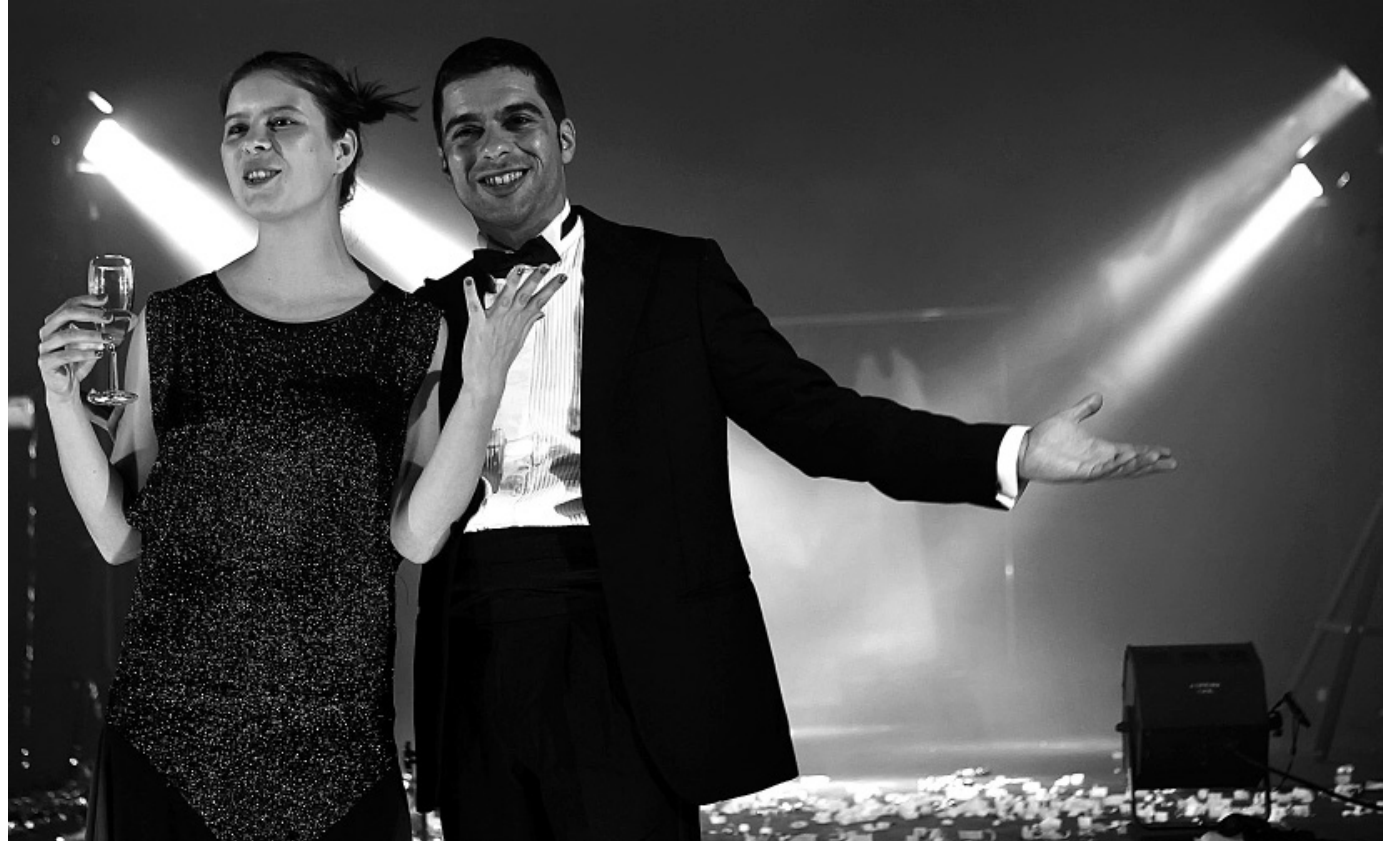

Titulo: Han Shot First. Criação e Interpretação: Diogo Bento e Inês Vaz. Figurinos: Dino Alves. Fotografia e Imagem gráfica: Alipio Padilha. Produção: Diogo Bento e Inês Vaz, Teatro da Garagem. Local e data de apresentação nos Festivais Gil Vicente: Café Concerto, Centro Cultural Vila Flor, 11 de Junho 2010

\section{Apresentação das estrelas}

\section{Stat Miller}

Inês Vaz e Diogo Bento, vestidos de gala, são os anfitriães da vernissage. Distribuem vinho, morangos, chocolates e biscoitos aos convidados nesta que consideram ser uma inauguração. Em discurso directo com o público, apresentam-se num exercicio de marketing de si próprios enquanto artistas e das suas capacidades de intérpretes. 0 que vemos em cena são eles, os actores, "Diogo e Inês" ou "Inês e Diogo", como preferirem, eles mesmos, e "mais um bocadinho". Não existem personagens: os dois discursam na primeira pessoa sobre os inícios, desde o início do mundo ao seu próprio início enquanto criadores. Falam da dificuldade dos princípios, das pressões sentidas e da dificuldade da profissão de actor. Fugindo à pretensão de querer criar qualquer espécie de ilusão dramática no espectador, o esqueleto cénico visivel (telão de projecção, figurinos, máquina de fumo, máquina de espuma), traduz a proposta do exercício: Han Shot First constitui-se como um momento cénico demonstrativo da capacidade destes actores em se exibirem e auto-promoverem, manipulando, sem esconder, os diversos truques cénicos.

Todo o exercício cénico, marcado por um tom irónico e sarcástico, se apresenta como uma Guerra das (futuras) estrelas, saga da qual os dois actores retiram o título para esta sua apresentação. É importante ter a coragem de dar o primeiro tiro, o primeiro passo e assumir esse risco de imediato. Han dispara primeiro, e esse acto é indubitável e absolutamente definidor do carácter desta personagem na narrativa dramática que dai decorre. 0 primeiro tiro, o primeiro passo é, sem dúvida, importante, pois é partir dele que nos lançamos no percurso da nossa própria narrativa.

0 discurso auto referencial do diálogo dos actores e os próprios dispositivos cénicos revelam uma inteligente forma artística de brincar com o público, de produzir 
espectáculo e de reclamar uma identidade criativa livre de pressões externas e procedimentos standard. Questionando as categorias e as temáticas de criação nas artes performativas, estes dois actores produzem a publicidade a si próprios, fazendo disso o espectáculo que publicita o próximo espectáculo e que será, mais uma vez, ele próprio, a publicidade aos dois actores que acabámos de ver em cena. Numa circularidade recorrente e infinita de um processo de experimentação artístico, em contacto directo com o público, Han Shot First manifesta-se como happening, privilegiando a relação com o público, uma vez que, em última análise, é esta relação com o espectador que determina o percurso do actor após o seu first shot.

\section{Potencial é espectáculo!}

Susana Chicó

À uma da manhã do penúltimo dia dos Festivais Gil Vicente, entramos no café-concerto do Centro Cultural Vila Flor onde decorre uma aparente inauguração com direito a beberete, salgadinhos e fotógrafo. Diogo Bento e Inês Vaz recebem os convidados de smoking e vestido de gala e, enquanto distribuem champanhe ao público, ouve-se uma contagem decrescente para o começo do espectáculo, que assim permanece durante uma hora, em constante recomeço. Inês Vaz e Diogo Bento propõem uma reflexão sobre o projecto, o arranque, e as primeiras vezes. 0 espectáculo é auto-reflexivo, explicativo e vagamente existencialista: se transforma todos os elementos de produção cénica e administrativa numa via temática dentro da qual os dois jovens criadores expõem ao público a sua condição artística iniciante numa espécie de apresentação oral (projectam-se PowerPoints onde figuram os seus currículos e a proposta aos apoios pontuais da DGArtes), é também sugerida uma reflexão existencial com narrações sobre o princípio e a origem, que passam pela teoria do Big Bang, pelo mito de Prometeu, e pela música We've Got Tonight, de Bob Seger e Sheena Easton, numa apologia pop ao momento efémero do espectáculo que os dois actores consideram estar a "encher de significação".

Diogo Bento e Inês Vaz não criam personagens. Apresentam-se como eles próprios, "e mais um bocadinho", pois é no ligeiro exagero que consiste a sua teatralidade. Mudam de roupa várias vezes, propondo, em figurinos bizarros e incompletos, um esboço, um início, que nunca se desenvolve nem se conclui. 0 espaço cénico é também incompleto. É um hibrido criado entre os bastidores e a ribalta, compondo-se por um charriô com figurinos, uma tela para projecção, máquinas de fumo e vento, projectores, e logótipos das instituições que apoiaram esta criação. Todos estes elementos são inventariados e explicados ao público nesta acção oca, e, talvez por isso, tão cativante.

Os dois actores, ligados ao Teatro Praga, bebem da influência estética auto-reflexiva e auto-irónica que caracteriza este grupo, mas depuram, com uma sobriedade notável, as referências histórico-filosóficas que os Praga tendem a ostentar de forma caótica e rebuscada. Este espectáculo celebra o potencial, e marca a importância da reacção e do recomeço, com uma comicidade leve e festiva. Aqui, louva-se o princípio como impulso intuitivo de sobrevivência, não sendo necessário um desenvolvimento, apenas um arranque.

\section{A procura de significação ou a redundância do nada?} Jorge Geraldo

Uma recepção de luxo, com champanhe, morangos e afins. Dois anfitriões vestidos de gala, com um ar extremamente afável e simpático recebem-nos no "seu" espaço e convidam-nos a sentar, avisam-nos que o espectáculo está prestes a começar. Na verdade todo este aparato é já parte da encenação.

0 espectáculo Han Shot First parte do trabalho de dois actores, Diogo Bento e Inês Vaz, que se propõem analisar a sequência de Star Wars, que George Lucas achou por bem alterar ao fim de 20 anos. No entanto, essa proposta surge envolta em discussões, músicas e deliberações sobre o que faz alguém agir. Propõem-se "encher de significação" o bocado que passam ali frente ao público, mas divergem nessa procura, iludindo-nos de forma hábil. Como a obra de Lucas, esta performance ultrapassa o espectáculo sendo em tudo um show, uma festividade, quase uma celebração.

A passagem por leitura de teatro, a clara aproximação ao cinema, os medleys musicais, assim como a utilização de diversos suportes como o vídeo, o fogo-de-artifício, não esquecendo a espuma, tudo serve para enriquecer o espectáculo, que não se deixa estrangular pelo espaço. Trata-se de uma obsessão com a escolha, uma obsessão pelo pormenor que, descontextualizado, perde a sua importância, ou mesmo a razão de existir. 
0 tom jocoso é pautado com algumas gargalhadas, muito boa disposição, mas parece claramente um espectáculo onde quem faz se diverte e se envolve muito mais do que quem vê. Há uma certa estranheza, um jogo de expectativas que parece nunca conseguir ir ao nosso encontro, ficando no entremeio, alheando-nos dos seus propósitos.
Não deixa de ser uma iniciativa de valor, com uma dupla jovem, arrojada e capaz, que utiliza tudo em prol do seu espectáculo, enviando-nos inclusive as suas saudações provenientes do passado, no momento mais delicioso do espectáculo.

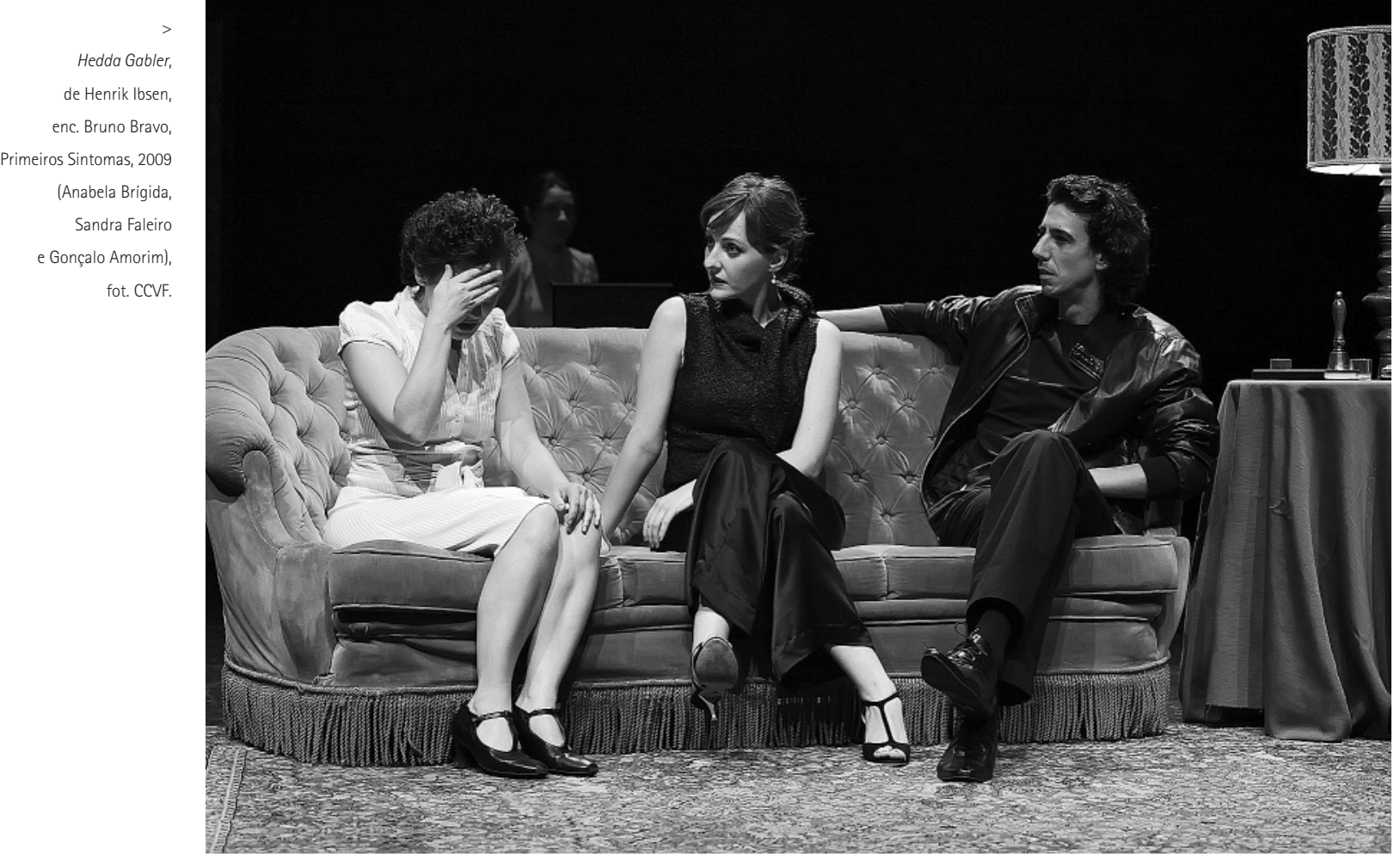

Titulo: Hedda Gabler. Texto: Henrik Ibsen. Tradução: João Paulo Esteves da Silva e Miguel Castro Caldas. Dramaturgia: Miguel Castro Caldas. Encenação: Bruno Bravo. Cenário: Stéphane Alberto. Figurinos: Ana Teresa Castelo. Desenho de luz: José Manuel Rodrigues. Interpretação: Anabela Brigida, Bruno Simões, David Almeida, Gonçalo Amorim, Inês Pereira, Sandra Faleiro, Raquel Dias. Produção: Primeiros Sintomas, Galeria Zẻ dos Bois. Local e data de apresentação nos Festivais Gil Vicente: Pequeno Auditório, Centro Cultural Vila Flor, 12 de Junho 2010

\section{Sem data}

Jorge Geraldo

0 grupo Primeiros Sintomas surge aqui com Hedda Gabler peça de Ibsen, numa clara aposta nos textos clássicos para experimentar o realismo, procurando novas direcções, de forma desafiante. Hedda é casada com Tesman, um casamento marcado pela falta de cumplicidade e pela manipulação e domínio maquiavélico de Hedda. Esta domina todas as personagens ao longo do espectáculo, manipulando-as a seu belo prazer, levando mesmo Lovborg, o mais dominado por Hedda, a cometer suicídio. No espectáculo ambos os actores vestem de negro, revelando a negra proximidade entre eles. 0 cenário é dominado por um sofá vermelho, em posição central, onde decorre a maior parte da acção, delimitando também a separação entre os diferentes espaços. Os adereços parcos, umas cadeiras, uma mesa, um candeeiro e um quadro, compõem o cenário de casa dos Tesman. Apesar de os actores já estarem em palco quando o público entra - e Lovborg sal mesmo da plateia para o palco - criando uma certa ligação com o espectador, a verdade é que a rigidez de movimentos e de performances rapidamente acabam por nos distanciar novamente da acção cénica. 0 início do espectáculo, quando as didascálias são lidas por uma das personagens, transporta-nos para o texto de lbsen, estabelecendo uma ligação com o texto original. 0 lado perverso e tenebroso de todas as personagens, autênticos abismos de terror, acaba por ser a nota dominante de todo o espectáculo, onde uma modesta Hedda acaba por parecer - mas nunca chega a ser - aquela mulher, aquela... Hedda. 